\title{
Variation of semen parameters in healthy medical students due to exam stress
}

\section{Fanuel Lampiao ${ }^{1}$}

1.College of Medicine, Blantyre, Malawi

\begin{abstract}
Aim

This study was aimed at investigating semen parameters that vary most in samples of healthy donors undergoing stressful examination period.
\end{abstract}

\section{Methods}

Samples were left to liquefy in an incubator at $37^{\circ} \mathrm{C}, 5 \%$ CO2 for 30 minutes before volume was measured. Concentration and motility parameters were measured by means of computer assisted semen analysis (CASA) using Sperm Class Analyzer ${ }^{\circledR}$ (Microptic S.L, Madrid, Spain).

\section{Results}

Sperm concentration was significantly decreased in samples donated close to the exam period as well as samples donated during the exam period when compared to samples donated at the beginning of the semester.

\section{Conclusion}

Stress levels of donors might prove to be clinically relevant and important when designing experiment protocols.

\section{Introduction}

Semen analysis is frequently used to evaluate male infertility. Assessment of semen quality is based on an evaluation of several parameters, including semen volume, $\mathrm{pH}$, sperm concentration, sperm motility, and sperm normal morphology. Seasonal variation in semen parameters have been reported in both fertile and infertile men ${ }^{1,2}$

Stress has been reported to be one of the most important health and social problems. It has long been suspected as having a very important impact on infertility in both males and females. Studies have shown that stress scores of infertile couples are much higher than those of fertile subjects ${ }^{3,4}$. This study was aimed at investigating semen parameters that vary most in samples of healthy donors undergoing stressful examination period.

\section{Materials and methods}

Donors recruited in this study provided informed consent for a research protocol approved by the University of Stellenbosch Ethics Committee. Semen samples were obtained from 15 healthy volunteers who were medical students in the second semester of 2008, at the beginning of the semester (August), close to examination (October) and during examination (November). All the donors had to observe a minimum of 2 days of sexual abstinence according to the World Health Organization ${ }^{5}$ before making a donation. Samples were left to liquefy in an incubator at $37^{\circ} \mathrm{C}, 5 \%$ CO 2 for 30 minutes before volume was measured. Concentration and motility parameters were measured by means of computer assisted semen analysis (CASA) using Sperm Class Analyzer ${ }^{\circledR}$ (Microptic S.L, Madrid, Spain). Parameters recorded were motile cells, progressive motility, rapid cells, average path velocity (VAP), straight line velocity (VSL), curvilinear velocity (VCL), amplitude of lateral head displacement (ALH), beat-cross frequency (BCF), Straightness (STR), linearity (LIN) and static cells. The results were analyzed on the GraphPad PrismTM 4 statistical program.

All data are expressed as mean \pm SEM. One-way analysis of variance (ANOVA) (with Bonferroni post hoc test if $p$ $<0.05$ ) was used for statistical analysis. Differences were regarded statistically significant if $\mathrm{p}<0.05$.

\section{Results}

As shown in Table 1, sperm concentration was significantly decreased in samples donated close to the exam period as well as samples donated during the exam period when compared to samples donated at the beginning of the semester, respectively. Straightness was also significantly decreased in samples donated during the examination period when compared to samples donated at the beginning of the semester. No significant differences were observed with other parameters.

\section{Discussion}

Although semen quality has been discussed extensively with respect to age, season and stress in the andrology literature, the results vary considerably and firm conclusions are still outstanding. To further our understanding of which parameters vary most due to examination stress in the semen samples of student donors, we analyzed samples donated at the beginning of the semester, close to the examination and during the end of second semester examination. This study has shown that sperm concentration significantly decreased in semen samples donated close to the examination period as well as during the examination period even though the decrease was not below the WHO cut-point of 20 million sperm cells per milliliter. Semen sample with a sperm count of less than 20 million/ $\mathrm{mL}$ are regarded as abnormal ${ }^{5}$. Other studies have also reported a decrease in semen quality due to stress. A study which analysed semen quality in a group of selected men showing a condition of psychological stress and an idiopathic infertility showed altered semen quality ${ }^{6}$. The study reported that necrosis and apoptosis were significantly higher in semen samples of men showing a condition of psychological stress and an idiopathic infertility. However, these results were reversed after the men had undergone stress therapy. This indicated that stress may be an additional risk factor for idiopathic infertility.

In this study, the motility parameter which decreased in samples collected during the examination period was straightness. Straightness can be defined as the linearity of the average path of the sperm5. Its decrease does not necessarily define the fertilization capability of spermatozoa. Apart from variations observed in other semen parameters such as volume, concentration and motility, it has also been reported that examination stress lead to a decrease in glutathione and free sulphydryl levels ${ }^{7}$. Glutathione and free sulphydryl are some of the very important antioxidants found in semen which protect spermatozoa from reactive oxygen species $(\mathrm{ROS})^{8,9}$. The decrease of glutathione and free sulphydryl in semen may lead to spermatozoa membrane lipid peroxidation and cell death cause by ROS thus explaining the low sperm concentrations observed in samples collected close to and 
during the examination period. In conclusion, stress levels of donors might prove to be clinically relevant and important when designing experiment protocols.

\section{References}

1.Saint P, Bauscart R, Leroy-Martin B, Herman E, Jablonski W. Circannual rhythms of sperm parameters of fertile men. Fertil Steril. 1989; 51: 1030-1033.

2.Centola GM, Eberly S. Seasonal variations and age-related changes in human sperm count, motility, motion parameters, morphology and white blood cell concentration. Fertil Steril. 1999; 72: 803-808.

3.Harrison RF, O'Moore RR, O'Moore AM. Stress and fertility: some modalities of investigation and treatment in couples with unexplained infertility in Dublin. Int J Fertil. 1986; 31: 153-159.

4.Boivin J, Shoog-Svanberg A, Andersson L, Hjelmstedt A, Bergh T, Collins A. Distress levels in men undergoing intracytoplasmic sperm injection versus in-vitro fertilization. Hum Reprod. 1998; 13: $1403-$ 1406.

5.World Health Organization. 1999. Who laboratory manual for theexamination of human semen and sperm-cervical mucus interaction. Cambridge University Press, Cambridge.

6.Collodel G, Moretti E, Fontani V, Rinaldi S, Aravagli L, Sarago G, Capitani S, Anichini C. Effect of stress on sperm quality. Indian J Med
Res. 2008;128: 254-261.

7.Eskiocak S, Gozen AS, Yapar SB, Tavas F, Kilic AS, Eskiocak M. Glutathione and free sulphydryl content of seminal plasma in healthy medical students during and after exam stress. Hum Reprod. 2005; 20 : 2595-2600.

8.Lewis SE, Boyle PM, McKinney KA, Young IS, Thompson W. Total antioxidant capacity of seminal plasma is different in fertile and infertile men. Fertil Steril. 1995; 64: 868-870.

9.Geva E, Lessing JB, Lerner-Geva L, Amit A. Free radicals, antioxidants and human spermatozoa: clinical implications. Hum Reprod. 1998; 13: $1422-1424$

Table 1. Different semen parameters of donors at the beginning of semister, close to examination and during examination period. ${ }^{*} p<0.05$ vs. Beginning of the semester:

\begin{tabular}{|c|c|c|c|}
\hline Parameters & Beginning of semister(August) & Close to examination(October) & During examinations(November) \\
\hline Volume (ml) & $3.64 \pm 0.16$ & $3.37 \pm 0.21$ & $3.40 \pm 0.22$ \\
\hline Concentration $\left(10^{6} \mathrm{ml}\right)$ & $54.95 \pm 5.92$ & $39.33 \pm 6.21$ & $37.44 \pm 2.43$ \\
\hline Motile(\%) & $83.95 \pm 4.70$ & $80.87 \pm 3.97$ & $88.37 \pm 2.29$ \\
\hline Progressive Motility(\%) & $59.69 \pm 4.82$ & $53.11 \pm 5.97$ & $60.70 \pm 3.49$ \\
\hline Average Path Velocity $(\mu \mathrm{m} / \mathrm{s})$ & $44.54 \pm 1.64$ & $36.31 \pm 3.43$ & $41.46 \pm 1.56$ \\
\hline Straight Line Velocity $(\mu \mathrm{m} / \mathrm{s})$ & $30.39 \pm 1.82$ & $22.19 \pm 2.56$ & $24.88 \pm 1.54$ \\
\hline Curvilinear Velocity $(\mu \mathrm{m})$ & $66.62 \pm 2.80$ & $56.03 \pm 4.49$ & $61.74 \pm 2.37$ \\
\hline $\begin{array}{c}\text { Amplitude of Lateral head Dis- } \\
\text { placement }(\mu \mathrm{m} / \mathrm{s})\end{array}$ & $1.90 \pm 0.06$ & $1.78 \pm 0.09$ & $1.86 \pm 0.07$ \\
\hline Beat-Cross Frequency $(\mathrm{Hz})$ & $13.86 \pm 0.87$ & $10.53 \pm 0.92$ & $11.33 \pm 0.80$ \\
\hline Straightness(\%) & $67.98 \pm 2.70$ & $60.43 \pm 1.70$ & $59.68 \pm 2.09$ \\
\hline Linearity $(\%)$ & $45.71 \pm 2.20$ & $38.23 \pm 1.85$ & $40.04 \pm 1.25$ \\
\hline Rapid Cells(\%) & $57.32 \pm 4.54$ & $51.04 \pm 6.16$ & $59.40 \pm 3.48$ \\
\hline Static Cells $(\%)$ & $16.15 \pm 4.68$ & $19.13 \pm 3.95$ & $11.74 \pm 2.27$ \\
\hline
\end{tabular}

